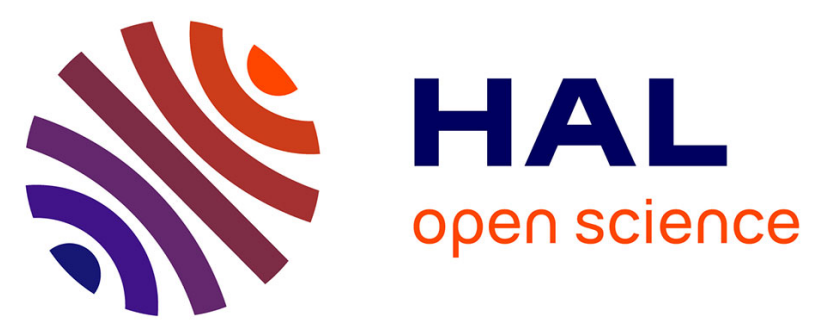

\title{
$\sigma$-Phase Formation in Super Austenitic Stainless Steel During Directional Solidification and Subsequent Phase Transformations
}

Raphaël Marin, Hervé Combeau, Julien Zollinger, Moukrane Dehmas, Bernard Rouat, Aude Lamontagne, Natalia Loukachenko, Lucile Lhenry-Robert

\section{- To cite this version:}

Raphaël Marin, Hervé Combeau, Julien Zollinger, Moukrane Dehmas, Bernard Rouat, et al.. $\sigma$ Phase Formation in Super Austenitic Stainless Steel During Directional Solidification and Subsequent Phase Transformations. Metallurgical and Materials Transactions A, 2020, 51 (7), pp.3526-3534. 10.1007/s11661-020-05794-1 . hal-02752428

\section{HAL Id: hal-02752428 \\ https://hal.science/hal-02752428}

Submitted on 9 Nov 2020

HAL is a multi-disciplinary open access archive for the deposit and dissemination of scientific research documents, whether they are published or not. The documents may come from teaching and research institutions in France or abroad, or from public or private research centers.
L'archive ouverte pluridisciplinaire HAL, est destinée au dépôt et à la diffusion de documents scientifiques de niveau recherche, publiés ou non, émanant des établissements d'enseignement et de recherche français ou étrangers, des laboratoires publics ou privés. 


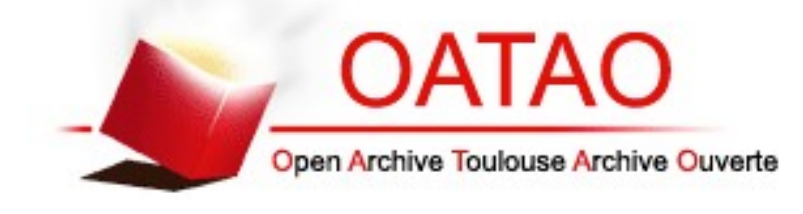

Open Archive Toulouse Archive Ouverte

OATAO is an open access repository that collects the work of Toulouse researchers and makes it freely available over the web where possible

This is an author's version published in: https://oatao.univ-toulouse.fr/26625

Official URL :

https://doi.org/10.1007/s11661-020-05794-1

\section{To cite this version:}

Marin, Raphaël and Combeau, Hervé and Zollinger, Julien and Dehmas, Moukrane and Rouat, Bernard and Lamontagne, Aude and Loukachenko, Natalia and Lhenry-Robert, Lucile $\sigma$-Phase Formation in Super Austenitic Stainless Steel During Directional Solidification and Subsequent Phase Transformations. (2020) Metallurgical and Materials Transactions A, 51 (7). 3526-3534. ISSN 1073-5623

Any correspondence concerning this service should be sent to the repository administrator: tech-oatao@listes-diff.inp-toulouse.fr 


\title{
$\sigma$-Phase Formation in Super Austenitic Stainless Steel During Directional Solidification and Subsequent Phase Transformations
}

\author{
RAPHAËL MARIN, HERVÉ COMBEAU, JULIEN ZOLLINGER, \\ MOUKRANE DEHMAS, BERNARD ROUAT, AUDE LAMONTAGNE, \\ NATALIA LOUKACHENKO, and LUCILE LHENRY-ROBERT
}

\begin{abstract}
The solidification path and the $\sigma$-phase precipitation mechanism in the S31254 (UNS designation) steel are investigated thanks to Quenching during Directional Solidification (QDS) experiments accompanied by scanning electron microscopy observations and electron backscattered diffraction (EBSD) analysis. Considering experimental conditions, the $\gamma$-austenite is found to be the primary solidifying phase $\left(1430{ }^{\circ} \mathrm{C}\right)$, followed by $\delta$-ferrite $\left(1400{ }^{\circ} \mathrm{C}, \approx 87 \mathrm{pct}\right.$ solid fraction). The $\sigma$-phase appears in the solid-state through the eutectoid decomposition of the $\delta$-ferrite: $\delta \rightarrow \sigma+\gamma_{2}\left(1210{ }^{\circ} \mathrm{C}\right)$, whereas the $\sigma$-phase is predicted to form from the austenite at $1096{ }^{\circ} \mathrm{C}$ in equilibrium conditions. The resulting temperatures of solidification path and phase transformation are compared with Gulliver-Scheil model and equilibrium calculations predicted using Thermo-Calc ${ }^{\odot}$ software. It is shown that the thermodynamics calculations agree with experimental results of solidification path. The EBSD analysis show that the $\delta$-ferrite has $\delta$ NW2 ORs with the $\sigma$-phase.
\end{abstract}

https://doi.org/10.1007/s11661-020-05794-1

\section{INTRODUCTION}

STAINLESS steels are an important class of materials. Their applications are countless, from basic applications such as sinks and hubcaps to very complex ones like aircraft fuselage and space vehicles. Stainless steels are rich in chromium (at least $11 \mathrm{wt}$ pct) in order to form a chromium oxide layer on the surface, which guards against pitting and rusting. However, stainless steels are most often used in more hostile environments such as desalination of seawater and petrochemical plants, ${ }^{[1-3]}$ which requires high corrosion resistance. Therefore, molybdenum is added to enhance resistance

RAPHAËL MARIN is with the Department of Metallurgy and Materials Science and Engineering, Institut Jean Lamour, UMR CNRS 7198, Université de Lorraine, 54000 Nancy, France, and with the CIRIMAT, Université de Toulouse, CNRS, Toulouse, France, and also with the Industeel, Centre de Recherche des Matériaux du Creusot (CRMC), 71200 Le Creusot, France. HERVÉ COMBEAU, JULIEN ZOLLINGER, and BERNARD ROUAT are with the Department of Metallurgy and Materials Science and Engineering, Institut Jean Lamour, UMR CNRS 7198, Université de Lorraine. Contact e-mail: julien.zollinger@univ-lorraine.fr MOUKRANE DEHMAS is with the CIRIMAT, Université de Toulouse, CNRS. AUDE LAMONTAGNE, NATALIA LOUKACHENKO, and LUCILE LHENRY-ROBERT are with the Industeel, Centre de Recherche des Matériaux du Creusot (CRMC). against pitting and rusting. During processing, due to the high content of alloying elements contained in these steels, it may be possible to form intermetallic precipitates enriched in chromium and molybdenum. The formation of these intermetallic precipitates removes $\mathrm{Cr}$ and Mo from the matrix, which lead to a significant decrease in the corrosion resistance of the steel. One of this intermetallic phase was found in 1907 by Treitschke and Tamman ${ }^{[4]}$ in the $\mathrm{Fe}-\mathrm{Cr}$ system. In 1927, a hard and brittle phase was found by Bain and Griffiths ${ }^{[5]}$ in the $\mathrm{Fe}-\mathrm{Cr}-\mathrm{Ni}$ system. This phase was called " $\sigma$-phase" in 1951 by Jett and Foote. ${ }^{[6]}$ The crystallographic structure of the $\sigma$-phase in the $\mathrm{Fe}$-Cr system was obtained by Bergmann and Shoemaker in $1951 .^{[7]}$ In 1966, the $\sigma$-phase was discovered in austenitic stainless steels by Hattersley and Hume-Rothery ${ }^{[8]}$ and Hall and Algie. ${ }^{[9]}$ Particularly, as-cast ingots exhibit $\sigma$-phase (space group 136 , tetragonal ${ }^{[10]}$ ) in interdendritic regions, which must be eliminated by heat treatments after solidification. Numerous studies are focused on the $\sigma$-phase formation during heat treatments of different class of stainless steels (ferritic, austenitic, and duplex). Two mechanisms of $\sigma$-phase precipitation are well established: (i) $\sigma$-phase nucleation in austenite ${ }^{[1-15]}$ and (ii) $\sigma$-phase nucleation from the eutectoid decomposition of the $\delta$-ferrite. ${ }^{[1,13,16-19]}$ However, few studies report on the $\sigma$-phase precipitation mechanism during the solidification in the stainless steels. Two scenarios are reported: it 
can be formed (i) during the last stage of the solidification through a eutectic reaction ${ }^{[20]}$ due to the segregation of the molybdenum in the liquid during the solidification stage, ${ }^{[21]}$ or (ii) during the decomposition of the $\delta$-ferrite dendrites, through a solid-state phase transformation. ${ }^{[22]}$

The purpose of this paper is to study the solidification path and the phase transformations of the super austenitic steel (UNS S31254). A Quenching during Directional Solidification (QDS) apparatus was used and coupled with Thermo-Calc ${ }^{(}$simulations to establish the solidification path and the $\sigma$-phase transformation mechanism of the steel. The crystallographic orientation relationships were determined using EBSD technique and compared with the literature.

\section{MATERIAL AND EXPERIMENTAL PROCEDURES}

\section{A. Material}

The steel used in this investigation was hot rolled grade, namely S31254 (UNS designation) and was provided by INDUSTEEL company. The nominal chemical composition (wt pct) is given in Table I.

The equilibrium liquidus and solidus temperatures of the S31254 steel were determined using a Setaram multi-detector high-temperature calorimeter apparatus. Three heating rates were applied, ranging from 2 to 10 ${ }^{\circ} \mathrm{C} / \mathrm{min}$. The equilibrium liquidus and solidus temperatures were found by extrapolation of the measurements to a $0{ }^{\circ} \mathrm{C} / \mathrm{min}$ heating rate. The equilibrium liquidus and solidus temperatures were found to be $1413{ }^{\circ} \mathrm{C} \pm 5^{\circ} \mathrm{C}$ and $1376{ }^{\circ} \mathrm{C} \pm 5^{\circ} \mathrm{C}$, respectively.

\section{B. Quenching During Directional Solidification}

The QDS experiments were performed with a Bridgman-type solidification setup, consisting of an induction furnace system and a water spraying cooling box, which was previously described by Charpentier et al. ${ }^{[23]}$ The melting and the directional solidification were performed under Helium gas flow. The samples were introduced in an alumina tube of $5-\mathrm{mm}$ inner diameter. The thermal history of the sample was recorded by a $\mathrm{Pt} /$ $\mathrm{Rh}$ B-type thermocouple located inside the sample and protected by an alumina tube. The top of the QDS sample was heated at a temperature higher than its melting point, while the rest of the QDS sample was heated at lower temperature and remaining thus solid. Once the interface between the liquid and the solid was stabilized, the directional solidification was achieved by pulling the alumina tube and the sample along the vertical axis at a constant solidification velocity $(V=5$

Table I. Nominal Chemical Composition of the S31254 Steel in Weight Percent

\begin{tabular}{ccccccccc}
\hline & $\mathrm{Fe}$ & $\mathrm{Cr}$ & $\mathrm{Ni}$ & $\mathrm{Mo}$ & $\mathrm{Cu}$ & $\mathrm{Mn}$ & $\mathrm{Si}$ & $\mathrm{N}$ \\
\hline S31254 & bal. & 19.68 & 17.77 & 6.08 & 0.67 & 0.65 & 0.20 & 0.19 \\
\hline
\end{tabular}

$\times 10^{-5} \mathrm{~m} / \mathrm{s}$ ). The solidification velocity was chosen in order to get a directional solidification and not a radial solidification. The thermal gradient $(\mathrm{G})$ was controlled by the temperature difference between the induction furnace and the water cooling box. At a constant solidification velocity, $\mathrm{G}$ controls the size of the different area on the sample, i.e., the thickness of the mushy zone. After a given solidified length, $10 \mathrm{~cm}$, the sample was quenched in order to freeze the microsegregation and the microstructure, by pulling it instantaneously through the cooling box, by a pneumatic piston fixed at the bottom of the alumina tube. The induced quenching rate was $100{ }^{\circ} \mathrm{C} / \mathrm{s}$. This experiment allows the solidification velocity $(V)$ and the thermal gradient $(G)$ to be monitored separately. After the QDS experiments, the sample was polished along the longitudinal section, which is parallel to the growth direction during the experiment. The temperature distribution along the sample was recorded by thermocouple in contact with the sample. In the present study, the average temperature gradient in the liquid phase and the mushy zone were $G=3{ }^{\circ} \mathrm{C} / \mathrm{mm}$ and $G=10^{\circ} \mathrm{C} / \mathrm{mm}$, respectively. These conditions are close to the solidification conditions at the center of the ingot.

\section{Microstructure Analysis}

The QDS samples were prepared using standard metallographic polishing. Final sample preparation was accomplished with colloidal silica. The microstructural observations were performed using a scanning electron microscope (SEM) Quanta FEG 650 in backscattered electron mode (BSE), operated at $20 \mathrm{kV}$. Electron back-scattered diffraction (EBSD) was used to precise the crystallography of the different phases and their crystallographic orientations. These investigations were performed with a HKL Nordlys II F+ EBSD camera. The step size was $0.2 \mu \mathrm{m}$ and the analyzed surface was $65 \mu \mathrm{m} \times 44 \mu \mathrm{m}$. Wavelength-dispersive X-ray spectroscopy (WDS) measurements were used to determine solid fraction in the mushy zone. The WDS analyses of the samples were realized with a JEOL JXA-8530 F which was equipped with 5 WDS spectrometers, 10 crystal analyzers. All analyses were made using a $20-\mathrm{kV}$ accelerating voltage and a beam current of $100 \mathrm{nA}$.

\section{Thermodynamics Calculations}

The Thermo-Calc ${ }^{\odot}$ software ${ }^{[24]}$ was used to predict the solidification path and the microsegregation evolution for lever-rule and Gulliver-Scheil corresponding assumptions. The calculations were conducted with the TCFe7 database. All the solute elements were accounted and all the possible phases were considered for the calculations. In addition to the equilibrium calculation, the non-equilibrium solidification simulations were realized with the Gulliver-Scheil model, which assumes infinite diffusion in the liquid phase and no diffusion in the solid phases for the substitutional solute elements. In these calculations, carbon and 
nitrogen are assumed to be fast diffuser and to follow thermodynamic equilibrium.

\section{RESULTS AND DISCUSSION}

\section{A. Experimental Solidification Path and Phase Transformations}

Figure 1(a) displays an optical micrograph of the longitudinal section from the top part of the QDS sample. Two different microstructures can be observed, the as-quenched remaining liquid on the top, and the mushy zone with columnar dendrites on the bottom. The yellow dotted line indicates the solidification front. The dendrite primary arms grow in a direction close to the thermal gradient, as a consequence of directional solidification. During the experiment, as the thermocouple position is known, it is thus possible to access to the thermal history of the sample as a function of time and distance. The QDS sample thermal history as a function of time is shown in Figure 1(b). The red curve represents the evolution of the temperature with time. Three different slopes can be observed. The first slope corresponds to the temperature evolution in the liquid phase. The thermal gradient in the liquid phase was determined to be $2.9{ }^{\circ} \mathrm{C} / \mathrm{mm}$. The second slope is associated with the mushy zone. The thermal gradient determiner in this zone was equal to $10.6^{\circ} \mathrm{C} / \mathrm{mm}$. In the fully solidified zone (third slope), the thermal gradient was $12.5{ }^{\circ} \mathrm{C} / \mathrm{mm}$. Particular temperatures such as the liquidus temperature, assuming the dendrite tip undercooling negligible, and the end of solidification were determined by fitting tangential lines to the temperature evolution (as can be seen in Figure 1(b)).

The first tangential line was drawn to fit the thermal signal in the liquid, and the second one to fit the thermal signal in the mushy zone. The intersection of the two tangential lines gives the dendrites tip solidification temperatures. An uncertainty of $\pm 10{ }^{\circ} \mathrm{C}$ on the temperature determination was considered, due to the thermocouple accuracy. The same procedure was used to determine the end of solidification temperature. Thus, the solidification starts at $1430{ }^{\circ} \mathrm{C} \pm 10{ }^{\circ} \mathrm{C}$ and ends at $1345^{\circ} \mathrm{C} \pm 10^{\circ} \mathrm{C}$ on the sample presented in Figure 1. Using the solidification start temperature, the thermal gradient in the different phases, and the position of the dendrite tips, it is possible to know the temperature at every position of the sample. There is a difference between the tip temperature measured with this method and the temperature obtained by DTA measurements $\left(1413{ }^{\circ} \mathrm{C}\right)$. A variability of $7{ }^{\circ} \mathrm{C}$ was observed for the tip temperature in between the different samples prepared by the QDS method. This difference between DTA and QDS samples might be due to the uncertainty on the thermocouple, the one associated by the temperature determination from each methods, and also minor changes in the chemical composition of the steel.

Figure 2 shows the evolution of the microstructure during the solidification stage with the corresponding temperatures. The temperature decreases from the top to the bottom of the figure. On the right side of Figure 2, the microstructure of the different locations of the QDS
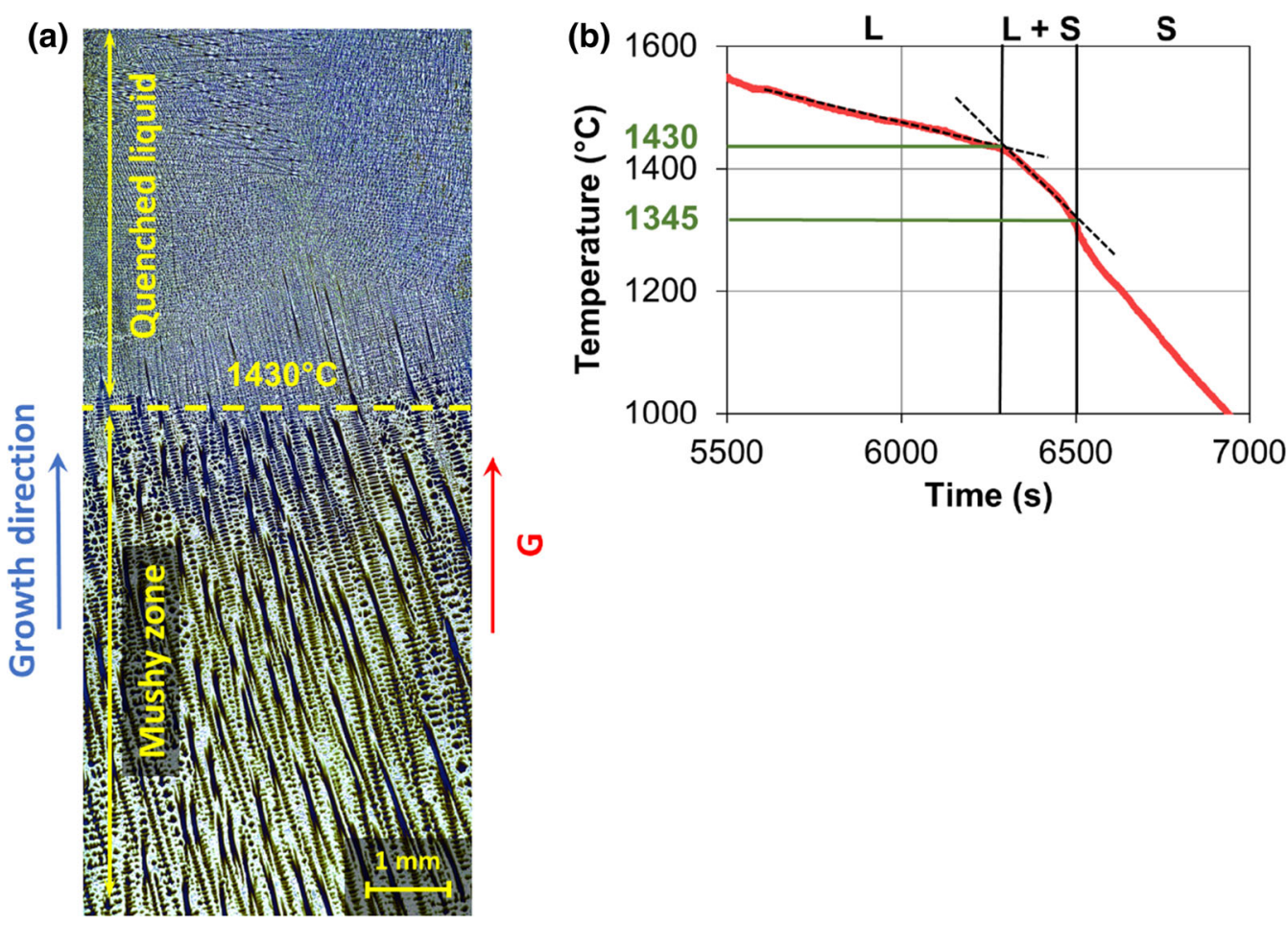

Fig. 1-QDS results, (a) optical micrograph showing quenched liquid and mushy zone after LB (Lichtenegger and Blöch) etching (60 g $\mathrm{NH}_{4} \mathrm{HF}_{2}, 2 \mathrm{~g} \mathrm{KHSO}_{3}$ and $100 \mathrm{~mL}$ of hot distilled water at $80{ }^{\circ} \mathrm{C}$ ), (b) temperature evolution of the sample measured by the $\mathrm{Pt} / \mathrm{Rh} \mathrm{B}$-type thermocouple. 

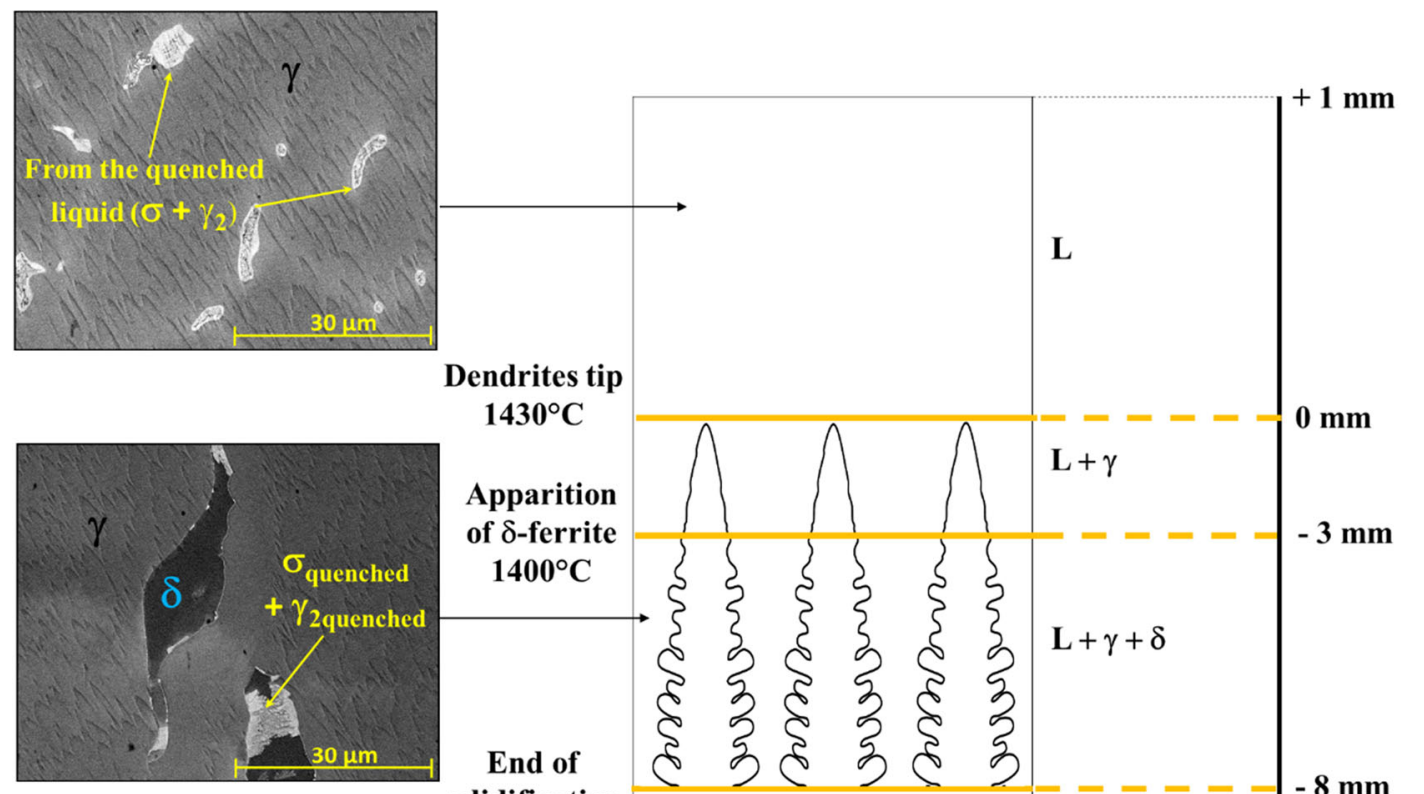

$1430^{\circ} \mathrm{C}$

Apparition of $\delta$-ferrite $1400^{\circ} \mathrm{C}$
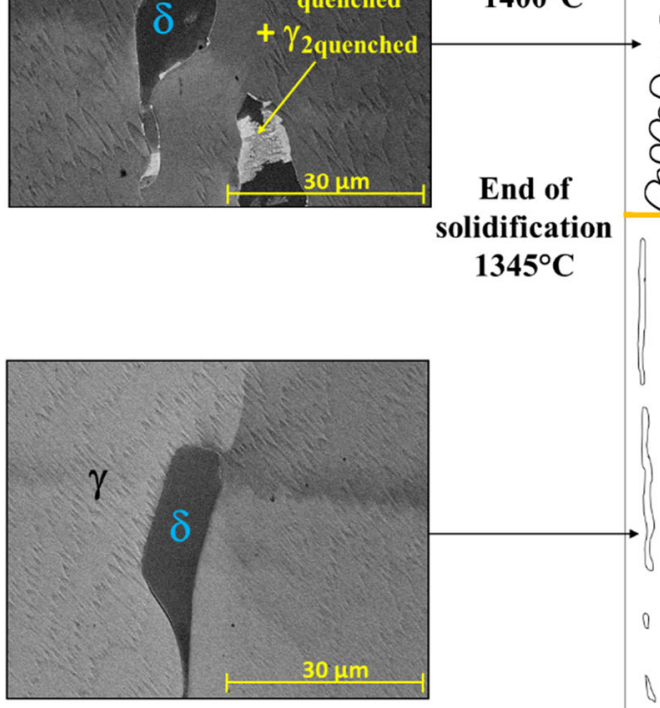

solidification $1345^{\circ} \mathrm{C}$
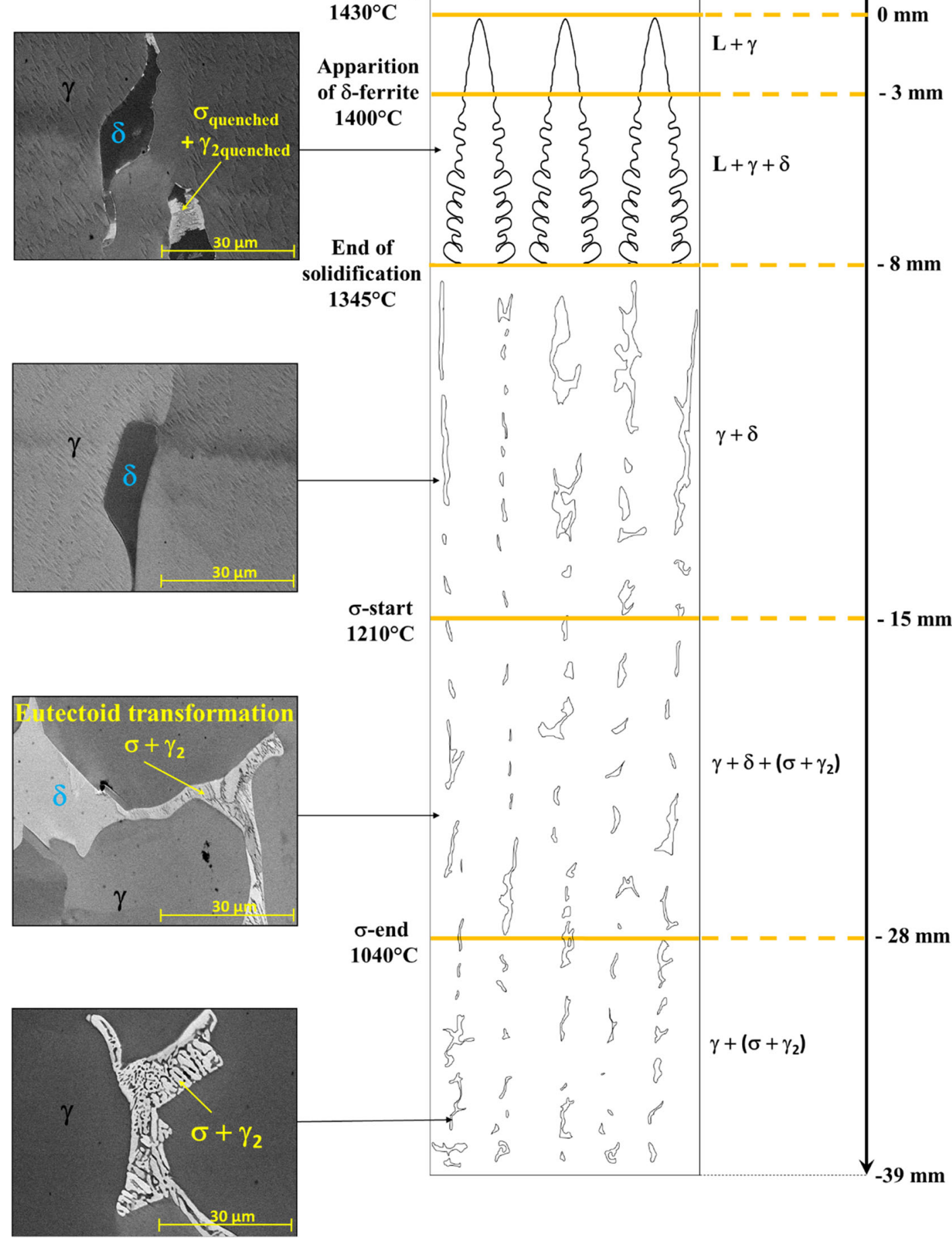

Fig. 2-SEM observations at the different locations of the QDS sample. Schematic representation of the microstructure on the right side. The vertical scale bar on the right side indicates the size of each location. 
sample was schematized. The phases at the different locations (i.e., mushy zone and solid-state) were identified by EBSD analysis. Two different types of $\sigma$ phase and $\gamma$-austenite islands were observed. The first type of islands, which is present in the quenched liquid and the mushy zone, is formed from the liquid phase during quenching to room temperature. These islands have a very thin microstructure with an interlamellar spacing of $300 \mathrm{~nm}$. The second one is much coarser (interlamellar spacing $\geq 1 \mu \mathrm{m}$ ) and corresponds to the $\sigma$-phase formed during the directional solidification process. The solidification starts with primary $\gamma$-austenite dendrites at $1430{ }^{\circ} \mathrm{C}$. At $1400{ }^{\circ} \mathrm{C}$, in the mushy zone, $\delta$-ferrite grows in the interdendritic spaces, stabilized by the molybdenum segregation in the liquid during solidification. ${ }^{[21]}$ The molybdenum apparent partition coefficient was determined by EDX measurements and is approximately equal to 0.68 , which is close to the value predicted by Thermo-Calc ${ }^{\odot}(0.69)$. The complete solidification occurs at $1345^{\circ} \mathrm{C}$. Below this temperature, the microstructure consists of $\gamma$-austenite dendrite and $\delta$-ferrite in the interdendritic areas. As previously mentioned, the formation of $\sigma$-phase in the quenched liquid and the mushy zone is due to high cooling rate from the quench; thus, we can conclude that no $\sigma$-phase was formed during the solidification period. At the solid-state, from $1345^{\circ} \mathrm{C}$ to $1210{ }^{\circ} \mathrm{C}$, the microstructure is characterized by $\gamma$-austenite dendrites and $\delta$-ferrite. Below $1210{ }^{\circ} \mathrm{C}$, a partial decomposition of the $\delta$-ferrite into $\sigma$-phase and secondary austenite $\left(\gamma_{2}\right)$ occurs. This decomposition starts at $1210{ }^{\circ} \mathrm{C}$ and ends at $1040{ }^{\circ} \mathrm{C}$. Below $1040{ }^{\circ} \mathrm{C}$, the $\delta$-ferrite is fully transformed into $\sigma$-phase and $\gamma_{2}$ and the microstructure consists of austenite dendrites surrounded by $\sigma+\gamma_{2}$ mixture, as shown in Figure 2.

Based on these results, the solidification path and solid-state phase transformation of the $\mathrm{S} 31254$ steel can be expressed as follows:

$$
\begin{aligned}
& \mathrm{L} \stackrel{1430^{\circ} \mathrm{C}}{\rightarrow} \mathrm{L}+\gamma \stackrel{1400^{\circ} \mathrm{C}}{\rightarrow} \mathrm{L}+\gamma+\delta \stackrel{1345^{\circ} \mathrm{C}}{\rightarrow} \gamma+\delta \stackrel{1210^{\circ} \mathrm{C}}{\rightarrow} \gamma+\delta \\
& \quad+\left(\sigma+\gamma_{2}\right) \stackrel{1040^{\circ} \mathrm{C}}{\rightarrow} \gamma+\left(\sigma+\gamma_{2}\right)
\end{aligned}
$$

\section{B. Solidification Path: Comparison Between Experimental and Numerical Results}

Table II compares the solidification interval determined from the DTA sample, QDS sample and from non-equilibrium and equilibrium Thermo-Calc ${ }^{(}$

Table II. Experimental and Calculated Solidification Interval of the S31254 Steel

Solidification Interval $\left({ }^{\circ} \mathrm{C}\right)$

\begin{tabular}{lr}
\hline Equilibrium (DTA) & 37 \\
QDS Sample & 85 \\
Gulliver-Scheil condition & 124 \\
$\quad$ (99.9 Pct Solid) & \\
Equilibrium Condition & 32 \\
\hline
\end{tabular}

calculations. The solidification interval calculated under non-equilibrium condition is larger $\left(124{ }^{\circ} \mathrm{C}\right)$ than the solidification interval obtained experimentally with QDS experiment $\left(85^{\circ} \mathrm{C}\right)$; this difference can be explained by the assumptions of the Gulliver-Scheil model. ${ }^{[25]}$ This model assumes no diffusion in the solid phase for the substitution elements and an infinite diffusion in the liquid phase. In real conditions, the diffusivity of solute elements is nonzero into the solid and finite into the liquid during the solidification process. In the case of the equilibrium conditions, the solidification interval $\left(32{ }^{\circ} \mathrm{C}\right)$ is close to the DTA result $\left(37^{\circ} \mathrm{C}\right)$ and also larger than the solidification interval obtained experimentally with QDS experiment.

Figure 3 compares the solidification paths obtained experimentally and numerically by considering the equilibrium conditions (level rule) and the Gulliver-Scheil assumptions. The temperature difference from the liquidus temperature as a function of solid fraction was considered. The undercooling of the dendrite tips was estimated with LGK model ${ }^{[26]}$ and is equal to $2{ }^{\circ} \mathrm{C}$; it will be neglected in the following analysis. In the case of the experimental results, the solid fractions at different temperatures were estimated by image analysis (IA) from cross sections of the QDS sample and WDS measurements. The solid fraction in the mushy zone of the QDS sample is plotted in orange squares (IA) and blue squares (WDS). In the mushy zone of the QDS sample, the solid fractions measured with the two different methods were found to be close, except for the first point which corresponds to the lowest solid fraction. This can be explained by the fact that during the quenching, the $\gamma$-austenite dendrites will experience growth that induces a large error in measurement by image analysis as shown by Pompe and Rettenmayr. ${ }^{[27]}$ For this reason, the solid fraction of this point is probably likely overestimated. The solid fractions determined experimentally were found to be close to the Gulliver-Scheil solidification path.

From these results, three different solidification paths can be described:

The equilibrium solidification path as computed from Thermo-Calc ${ }^{\odot}: \mathrm{L}+\gamma \stackrel{32^{\circ} \mathrm{C}}{\rightarrow} \gamma$

The experimental solidification path: $\mathrm{L}+\gamma \stackrel{30^{\circ} \mathrm{C}}{\rightarrow} \mathrm{L}+\gamma+\delta \stackrel{85^{\circ} \mathrm{C}}{\rightarrow} \gamma+\delta$

The Gulliver-Scheil solidification path computed from Thermo-Calc ${ }^{\complement}$ :

$$
\mathrm{L}+\gamma \stackrel{24^{\circ} \mathrm{C}}{\rightarrow} \mathrm{L}+\gamma+\delta \stackrel{74^{\circ} \mathrm{C}}{\rightarrow} \gamma+\sigma \stackrel{124^{\circ} \mathrm{C}}{\rightarrow} \gamma+\delta+\sigma
$$

Considering the equilibrium conditions, the microstructure is fully austenitic at the end of the solidification, which is not the case for the experimental result and the non-equilibrium calculation. The $\delta$-ferrite temperature formation for the QDS sample $\left(30{ }^{\circ} \mathrm{C}\right.$ below the liquidus temperature) is quite close to the Gulliver-Scheil calculation $\left(24{ }^{\circ} \mathrm{C}\right.$ below the liquidus temperature). However, the solid fractions are different: 85 pct solid for the QDS sample and 65 pct for the 


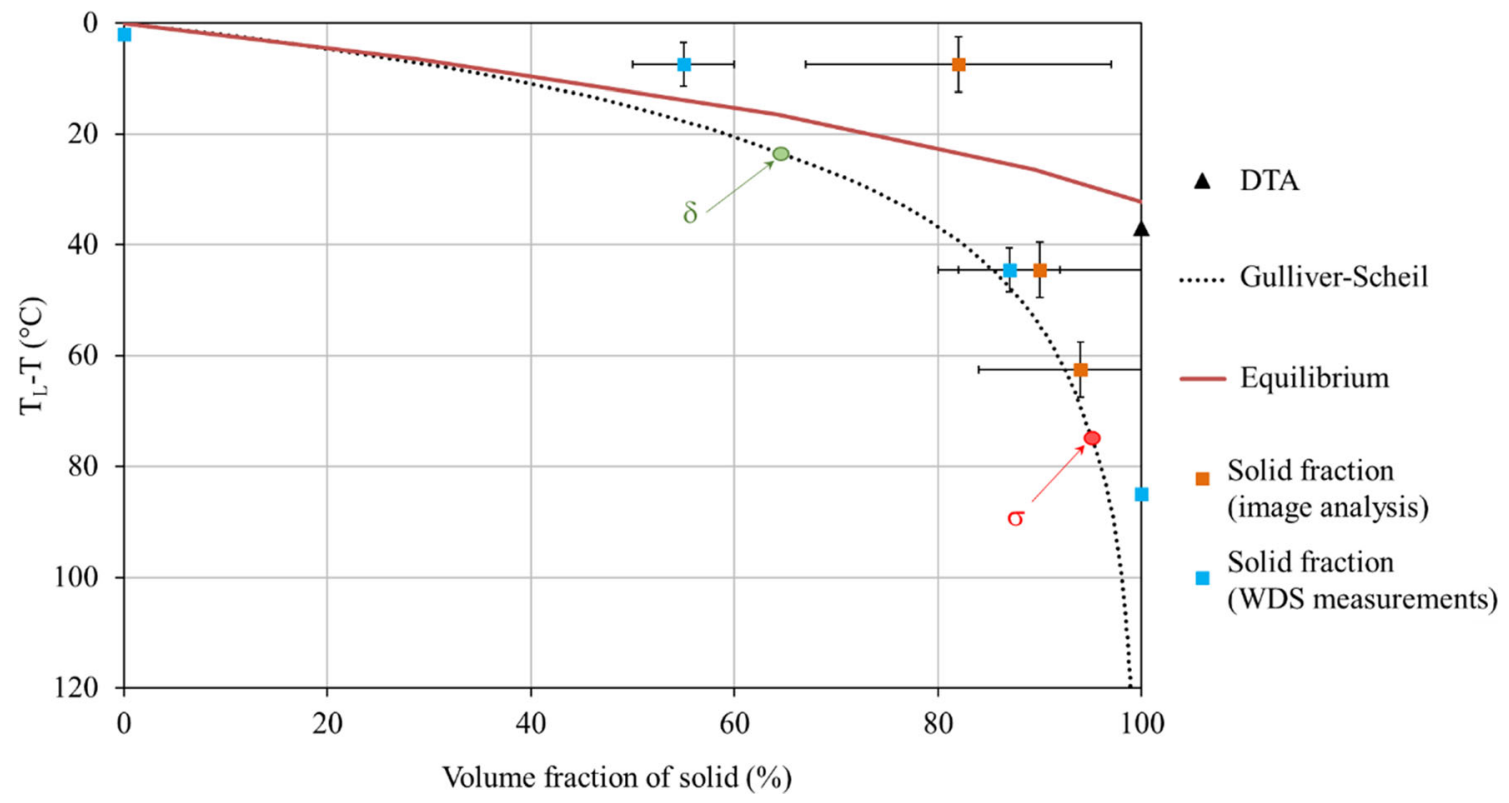

Fig. 3-Experimental and numerical solidification path. Experimental data are given with the orange squares (image analysis) and blue squares (WDS measurements), equilibrium conditions are plotted with a dashed line and Gulliver-Scheil conditions are represented with a black dotted line. Arrows and dots represent the phases involved during the solidification process (Color figure online).

non-equilibrium calculation. Moreover, the equilibrium calculations showed the beginning of $\sigma$-precipitation at $1096{ }^{\circ} \mathrm{C}$ in the solid state from austenite, while the formation of $\sigma$-phase starts at $1210{ }^{\circ} \mathrm{C}$ from $\delta$-ferrite in the QDS sample. This finding highlights the importance of microsegregation during the solidification of the S31254 on the sequence of precipitation. It leads to an increase of the $\sigma$-phase precipitation temperature despite the back-diffusion in the solid.

The importance of the back-diffusion in the solid during microsegregation was estimated with the model developed by Brody and Flemings. ${ }^{[28]}$ Since chromium and nickel have partition coefficient close to unity, only the microsegregation of the molybdenum was considered $\left(k_{\mathrm{Mo}} \approx 0.67\right)$. The Fourier number obtained with the experimental data is close to 0 (0.0117), which correspond to Gulliver-Scheil assumptions. The comparison between the experimental $\left(85^{\circ} \mathrm{C}\right)$ and modeled solidification interval $\left(84{ }^{\circ} \mathrm{C}\right)$ shows that considering microsegregation leads to a better agreement between experimental and modeling for the investigated processing conditions.

It has been shown that the $\sigma$-phase does not precipitate during the solidification for the investigated processing conditions. However, it might be possible to form $\sigma$-phase during solidification directly from the liquid phase in the case of rapid cooling. As an example, Lee et al. ${ }^{[29]}$ reported the presence of $\sigma$-phase in a super austenitic weld sample, in the interdendritic space. Figure 4 represents a quaternary phase diagram (Fe-Cr-Mo-Ni) showing the difference of liquidus temperature between the phases as a function of the chemical composition. For each chemical composition, three different systems were considered with only two phases per system: $\mathrm{L}+\gamma, \mathrm{L}+\delta, \mathrm{L}+\sigma$. The liquidus temperatures for each system were obtained and compared. These results were obtained with ThermoCalc $^{(}$calculations. The chemical composition was modified for each calculation. Chromium, nickel, and molybdenum were considered in the range of 15 to $35 \mathrm{wt}$ pct, 10 to $30 \mathrm{wt}$. pct and 5 to $25 \mathrm{wt}$. pct, respectively. The minor solute elements $(\mathrm{C}, \mathrm{N}, \mathrm{Mn}, \mathrm{Cu}$, and $\mathrm{Si}$ ) were considered as constants with values of the nominal composition.

The experimental values, represented by green and black points correspond to the average chemical composition of the liquid from the QDS sample at 55 and 87 pct volume solid fraction, respectively. The red point corresponds to the nominal composition of the steel.

Figure 4(a) represents the temperature difference between austenite liquidus temperature and $\delta$-ferrite liquidus temperature for each chemical composition and figure $4 \mathrm{~b}$ gives the temperature difference between $\delta$-ferrite liquidus temperature and $\sigma$-phase liquidus temperature.

The transition from a phase to another happens at $\Delta T=0{ }^{\circ} \mathrm{C}$, for example, in Figure 4(a) for positive temperature difference the austenite will be the stable phase but below $\Delta \mathrm{T}=0{ }^{\circ} \mathrm{C}, \delta$-ferrite will be the stable phase. Figure 4(a) shows that the formation of $\delta$-ferrite during the solidification stage is thermodynamically possible, and it corresponds to the experimental results. Figure 4(b) shows the existence of a driving force for the precipitation of $\sigma$-phase during solidification.

\section{Phase Transformation and Orientation Relationship}

Figures 5 displays the EBSD maps of the QDS sample in the solid-state location. It can be found former interdendritic regions undergoing the eutectoid transformation $\delta \rightarrow \sigma+\gamma_{2}$ surrounded by $\gamma$-austenite 

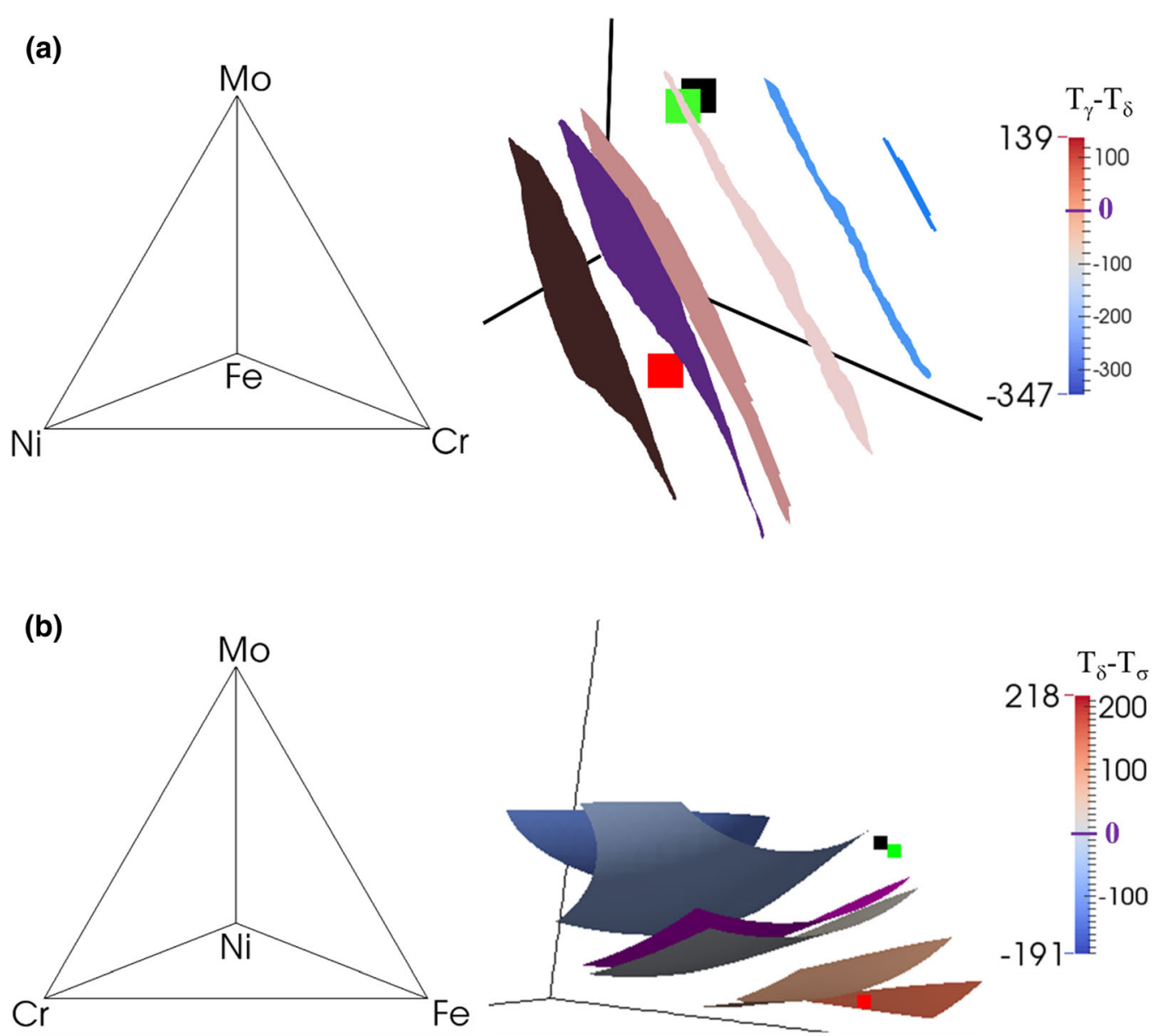

Nominal composition

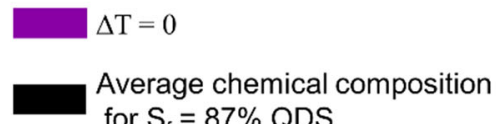

Average chemical composition for $S_{f}=55 \%$ QDS for $S_{f}=87 \%$ QDS

Fig. 4- Quaternary phase diagram (Fe-Cr-Mo-Ni) representing the difference of liquidus temperature between the different phases for each different chemical composition with temperature isosurface. (a) Between $\gamma / \delta$, (b) between $\delta / \sigma$. Red square corresponds to the nominal chemical composition of the steel, while green and black squares correspond to the average chemical composition of the liquid from the QDS sample at 55 and 87 pct volume solid fraction, respectively (Color figure online).

dendrites at $1129^{\circ} \mathrm{C}$. The crystalline phase structure is identified with a color code on Figure 5(a), the austenitic phase (FCC) is identified in red, while the $\delta$-ferrite (BCC) and the $\sigma$-phase (tetragonal) are in blue and yellow, respectively. The gray color corresponds to pixels that were not indexed due to the small size of the eutectoid microstructure. Figure 5(b) gives a crystallographic orientation map of the different phases on the EBSD map. The EBSD orientation map shows that the interdendritic precipitate partially is decomposed into $\sigma$ $+\gamma_{2}$, arose from a $\delta$-ferrite single grain. The analysis of the stereographic projection resulting from the EBSD map showed that the $\delta$-ferrite grains have an orientation relationship with the austenite dendrites with a small deviation (5 deg) between the growth directions.

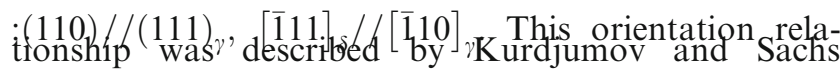

$(\mathrm{K}-\mathrm{S}) \cdot{ }^{[30]}$ This funding suggests that the $\delta$-ferrite nucleates at the $\mathrm{L} / \gamma$ interface during solidification.

Figure 5(c) displays three stereographic projection showing the ORs between $\delta$-ferrite and the $\sigma$-phase grains. The $\delta$-ferrite poles and directions are marked with blue closed symbols, and the three $\sigma$-phase grains $\sigma_{1}, \sigma_{2}$, and $\sigma_{3}$ with green, orange, and black open symbols, respectively. The analysis of the superposition of the stereographic projection extracted from the crystallographic orientation map showed that the $\{110\} \delta$ pole are superimposed with the three $\sigma$-phase variants $\left(\sigma_{1}, \sigma_{2}, \sigma_{3}\right)$, which share the same (001) pole and are a common interface with the same ferrite grain: $\{1 \overline{1} 0\}_{\delta} / /\{001\}_{\sigma}$. The two stereographic projection show that the $\delta$-ferrite and the three $\sigma$-phase variants exhibit two common direction types: $[110]_{\delta} / /[1 \overline{1} 0]_{\sigma}$ and $[00 \overline{1}]_{\delta} / /[110]_{\sigma}$. The $\delta$-ferrite holds an orientation relationship with the $\sigma$-phases grains $\left(\sigma_{1}, \sigma_{2}, \sigma_{3}\right)$. This 
(a) Phases

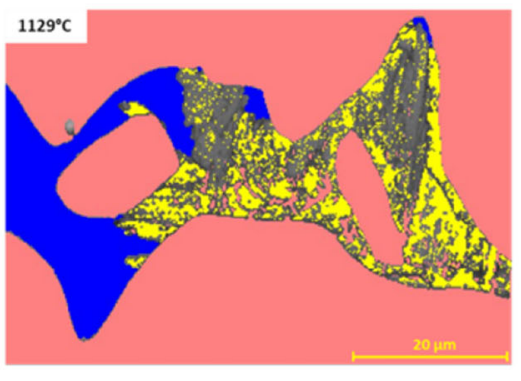

(b) Grain orientation

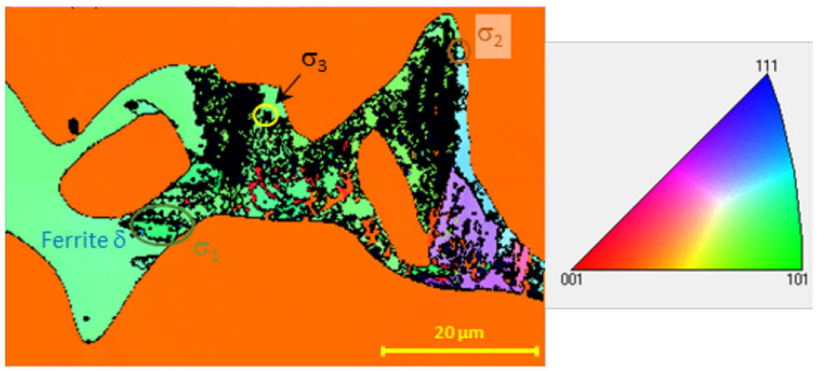

(c)
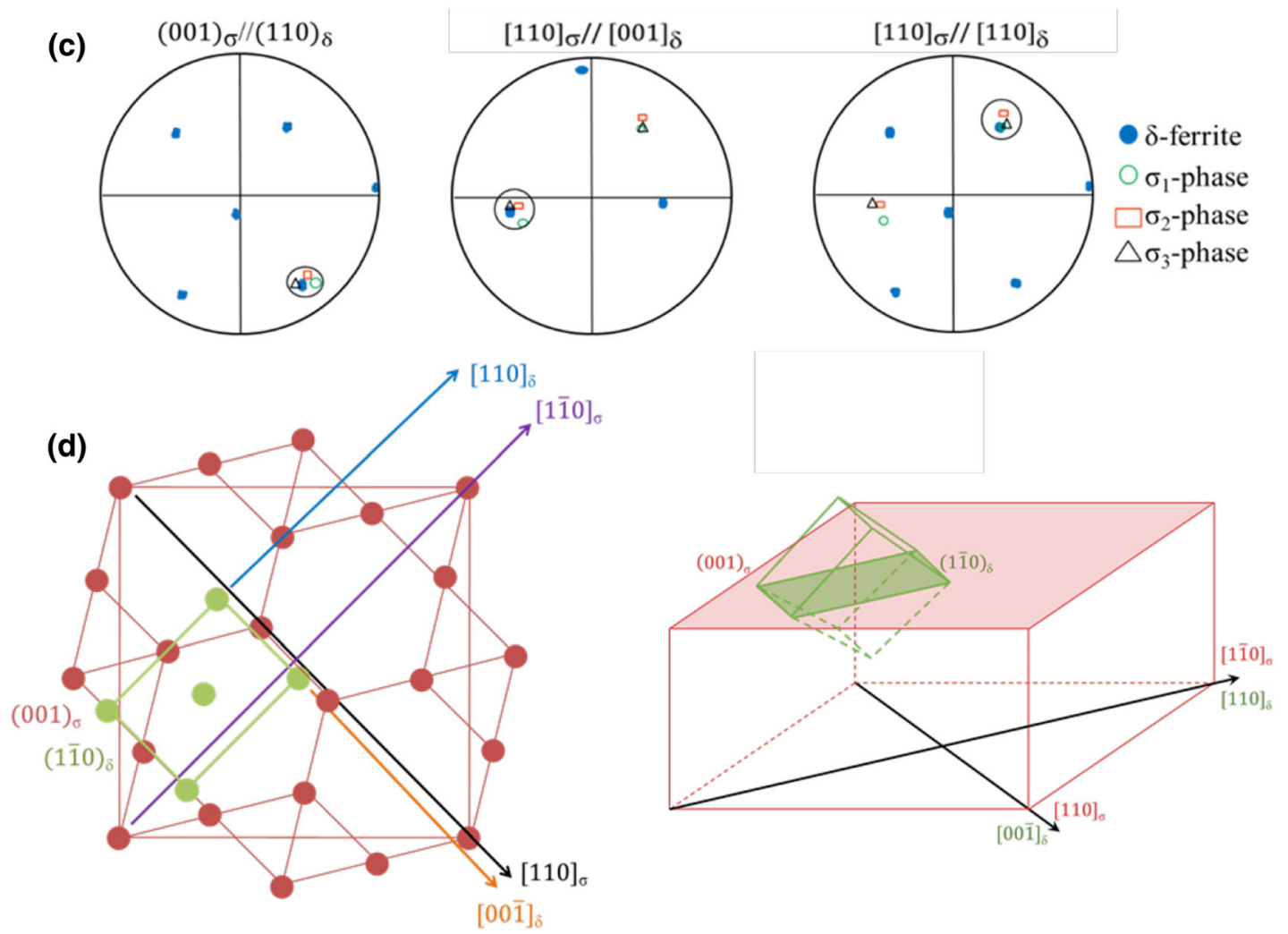

Fig. 5-EBSD maps, (a) phase identification, (b) grain orientation with IPF coloring, $(c)$ poles figures: overlaying of $(110)_{\delta} / /(001)_{\sigma}$, $[001]_{\delta} / /[110]_{\sigma}$ and $[110]_{\delta} / /[110]_{\sigma}$, showing the existence of $\delta \mathrm{NW} 2$ orientation relationship between $\delta$-ferrite and $\sigma$-phase. The black open circles show the matching pole, $(d)$ schematic representation of the superposition of the (001) $\sigma$-phase dense plan and the (110) $\delta$-ferrite dense plan following the $\delta \mathrm{NW} 2$ orientation relationship: $(1 \overline{1} 0)_{\delta} / /(001)_{\sigma}[110]_{\delta} / /[1 \overline{1} 0]_{\sigma}[00 \overline{1}]_{\delta} / /[110]_{\sigma}$.

orientation relationship is called $\delta \mathrm{NW} 2$ and was described by Redjaïmia. ${ }^{[30]}$ Small angle deviations are observed $(<5 \mathrm{deg})$ from the coplanar and collinear conditions. Figure $5(\mathrm{~d})$ shows the projection of the $\sigma$-phase dense plane $(001)$ and $\delta$-ferrite dense plane $(1 \overline{1} 0)$ respecting common directions and lattice parameters of each phase. The $\sigma$-phase lattice parameters were obtained by TEM measurements and $\delta$-ferrite lattice parameters were obtained for literature. The secondary austenite $\left(\gamma_{2}\right)$, resulting from the $\delta$-ferrite eutectoid decomposition, grew at the $\delta / \sigma$ interface and showed a $\mathrm{K}-\mathrm{S}$ OR with the $\delta$-ferrite. Redjaïmia ${ }^{[31]}$ reported that the transformation of $\delta$-ferrite into $\sigma$-phase was due to small shifts, with a value less than the interatomic distance. On Figure 5(d) the atomic rows are parallel to direction $[110]_{\delta}$ and $[1 \overline{1} 0]_{\sigma}$. The atomic distribution on these two rows is almost identical, the transformation from the $\delta$-ferrite to $\sigma$-phase requires only small adjustments of the atomic positions when the $\delta \mathrm{NW} 2$ orientation relationship is verified. The existence of ORs between $\delta$-ferrite and $\gamma$ phases leads to reduce the interfacial energy required to nucleate $\sigma$-phase on the interface. However, an investigation conducted by Sato et al. ${ }^{[32]}$ in a duplex stainless steels showed that a higher crystallographic misorientation between the austenitic and ferritic phases favored $\sigma$-phase precipitation. Redjaïmia proposed a transformation mechanism ${ }^{[25]}$ : the $\sigma$-phase nucleation starts at the interface $\delta / \gamma$ and grows in the $\delta$-ferrite with a lamellar morphology, due to the presence of $\mathrm{Cr}$ and Mo in $\delta$-ferrite, which have higher diffusivity. The partitioning of the $\sigma$ favoring elements $(\mathrm{Cr}, \mathrm{Mo})$ leads to the growth of the lamellae while the $\mathrm{Fe}$ 
and $\mathrm{Ni}$ are rejected in the $\delta$-ferrite. This diffusion length of solute elements is short through the $\delta / \sigma$ interface and locally modifies the chemical composition of the $\delta$-ferrite from the $\delta / \sigma$ interface. The partitioning destabilizes the $\delta$-ferrite and causes its decomposition into austenite $\left(\gamma_{2}\right)$ and $\sigma$-phase. A mixture of $\sigma+\gamma_{2}$ lamellar morphology is obtained and grows at the expense of the $\delta$-ferrite. As a part of a future work, the phase transformation should be described with a diffusion model to improve the comprehension of these results and composition profiles at the interface between the $\gamma$-austenite dendrites and the $\sigma$-phase and $\sigma$-phase $/ \gamma_{2}$.

\section{CONCLUSION}

Directional solidification of the S31254 alloy was investigated through QDS experiments. In addition to the solidification path, it has been showed that information on the solid-state transformations can also be obtained from the quenching that is performed. Considering experimental conditions, the austenite was found to be the primary solidifying phase, followed by $\delta$-ferrite in the interdendritic area, due to the segregation of molybdenum. It was shown that the austenite dendrites have $\mathrm{K}-\mathrm{S}$ ORs with the $\delta$-ferrite. Gulliver-Scheil microsegregation model was in agreement with experimental results, especially for the solidification path. During the solidification, the microsegregation intensity was slightly decreased by the back diffusion in the solid. At the solid state, the $\sigma$-phase appears through an eutectoid decomposition of the $\delta$-ferrite: $\delta \rightarrow \sigma+\gamma_{2}$. The EBSD analysis showed that the $\delta$-ferrite has $\delta$ NW2 ORs with the $\sigma$-phase. Finally, this study proposes the following solidification path and the $\sigma$-phase precipitation mechanism for the $\mathrm{S} 31254$ steel:

$$
\begin{aligned}
& \mathrm{L} \stackrel{1430^{\circ} \mathrm{C}}{\rightarrow} \mathrm{L}+\gamma \stackrel{1400^{\circ} \mathrm{C}}{\rightarrow} \mathrm{L}+\gamma+\delta \stackrel{1345^{\circ} \mathrm{C}}{\rightarrow} \gamma+\delta \stackrel{1210^{\circ} \mathrm{C}}{\rightarrow} \gamma+\delta \\
& \quad+\sigma+\gamma_{2} \stackrel{1040^{\circ} \mathrm{C}}{\rightarrow} \gamma+\sigma+\gamma_{2}
\end{aligned}
$$

\section{ACKNOWLEDGMENTS}

The assistance of E. Etienne and S. Mathieu (Centre de Compétences Microscopie, Microsondes et Métallographie, CC3M, Institut Jean Lamour) for the EBSD preparation and analysis was greatly appreciated. Financial support from Industeel and ANRT under a CIFRE Ph.D. fellowship (Grant Number 2016-0780) is gratefully acknowledged.

\section{REFERENCES}

1. J.K.L. Lai, C.H. Shek, and K.H. Lo: Stainless Steels: An Introduction and Their Recent Developments, Bentham Science Publishers, Beijing, 2012.

2. G. Stein, I. Hucklenbroich, and H. Feichtinger: in Materials Science Forum, vol. 318, Trans Tech Publ, 1999, pp. 151-60.

3. J. Olsson and K. Minnich: Desalination, 1999, vol. 124, pp. 85-91.

4. W. Treitschke and G. Tammann: Anorganische Chem., 1907, vol. 55 , p. 707.

5. E.C. Bain and W.E. Griffiths: Trans. AIME, 1927, vol. 75, pp. 166-211.

6. E.R. Jett and F. Foote: Met. Alloys, 1936, vol. 7, pp. 207-10.

7. B.G. Bergman and D.P. Shoemaker: J. Chem. Phys., 1951, vol. 19, pp. 515-15.

8. B. Hattersley: J. Iron Steel Inst., 1966, vol. 204, pp. 683-701.

9. E.O. Hall and S.H. Algie: Metall. Rev., 1966, vol. 11, pp. 61-88.

10. T. Koutsoukis, A. Redjaïmia, and G. Fourlaris: Mater. Sci. Eng. A, 2013, vol. 561, pp. 477-85.

11. I.F. Machado and A.F. Padilha: ISIJ Int., 2000, vol. 40, pp. 719-24.

12. T. Koutsoukis, A. Redjaïmia, and G. Fourlaris: in Solid State Phenomena, vol. 172, Trans Tech Publ, 2011, pp. 493-98.

13. T. Koutsoukis, K. Konstantinidis, E.G. Papadopoulou, P. Kokkonidis, and G. Fourlaris: Mater. Sci. Technol., 2011, vol. 27, pp. 943-50.

14. T.-H. Lee, S.-J. Kim, and Y.-C. Jung: Metall. Mater. Trans. A, 2000, vol. 31, pp. 1713-23.

15. C.-C. Hsieh and W. Wu: ISRN Metallurgy.

16. M. Pohl, O. Storz, and T. Glogowski: Mater. Charact., 2007, vol. 58 , pp. $65-71$.

17. C.C. Tseng, Y. Shen, S.W. Thompson, M.C. Mataya, and G. Krauss: Metall. Mater. Trans. A, 1994, vol. 25A, pp. 1147-58.

18. N. Llorca-Isern, H. López-Luque, I. López-Jiménez, and M.V. Biezma: Mater. Charact., 2016, vol. 112, pp. 20-29.

19. T.H. Chen and J.R. Yang: Mater. Sci. Eng. A, 2001, vol. 311, pp. 28-41.

20. M.J. Perricone and J.N. DuPont: Metall. Mater. Trans. A, 2006, vol. 37A, pp. $1267-80$.

21. S.W. Banovic, J.N. DuPont, and A.R. Marder: Sci. Technol. Weld. Joining, 2002, vol. 7, pp. 374-83.

22. C.-C. Hsieh, D.-Y. Lin, and T.-C. Chang: Mater. Sci. Eng. A, 2008, vol. 475, pp. 128-35.

23. M. Charpentier, D. Daloz, E. Gautier, G. Lesoult, A. Hazotte, and M. Grange: Metall. Mater. Trans. A, 2003, vol. 34, pp. $2139-48$.

24. B. Sundman, B. Jansson, and J.-O. Andersson: Calphad, 1985, vol. 9, pp. 153-90.

25. E. Scheil: in Bemerkungen zur schichtkristallbildung, Z. Metallkd., 1942, pp. 34-70.

26. J.A. Dantzig and M. Rappaz: Solidification: -Revised \& Expanded, EPFL Press, Boca Raton, 2016.

27. O. Pompe and M. Rettenmayr: J. Cryst. Growth, 1998, vol. 192, pp. 300-06.

28. H.D. Brody: Ph.D. Thesis, Massachusetts Institute of Technology, 1965.

29. C. Lee, S. Roh, C. Lee, and S. Hong: Mater. Chem. Phys., 2018, vol. 207, pp. 91-97.

30. G. Kurdjumow and G. Sachs: Zeitschrift für Physik, 1930, vol. 64, pp. 325-43.

31. A. Redjaïmia: Ph.D. Thesis, Vandoeuvre-les-Nancy, INPL, 1991.

32. Y.S. Sato and H. Kokawa: Scripta Mater. 